\title{
Association between intraosseous schwannoma occurrence and the position of the intraosseous nutrient vessel: A case report
}

\author{
KAYO SUZUKI $^{1}$, TAKETOSHI YASUDA ${ }^{1}$, KENTA WATANABE $^{1}$, \\ MASAHIKO KANAMORI $^{2}$ and TOMOATSU KIMURA ${ }^{1}$ \\ Departments of ${ }^{1}$ Orthopedic Surgery and ${ }^{2}$ Human Science 1, Faculty of Medicine, \\ University of Toyama, Toyama 930-0194, Japan
}

Received February 9, 2015; Accepted March 1, 2016

DOI: $10.3892 / \mathrm{ol} .2016 .4363$

\begin{abstract}
Intraosseous schwannoma is a rare benign bone tumor that originates from Schwann cells of the nerve sheath. The majority of intraosseous schwannomas arise in the mandible and sacrum, but an intraosseous schwannoma involving the ulna is described in the present case report. Radiologically, the current case presented as a well-defined lytic lesion, with a pathological fracture and no intralesional calcification, in the proximal metaphysis of the left ulna. Using magnetic resonance imaging, an intraosseous mass spreading out from the cortical defect was observed. The lesion appeared isointense to skeletal muscle on T1-weighted images, and hyperintense or heterogeneous on T2-weighted images. The differential diagnosis comprised benign bone tumors, including bone cyst, aneurysmal bone cyst, giant cell tumor and fibrous dysplasia. Based on the results of a needle biopsy, a schwannoma involving the ulnar bone was diagnosed, and tumor marginal resection followed by artificial bone grafting and fixation was performed. A total of one year subsequent to surgery, the patient exhibits no symptoms, and there is no evidence of disease recurrence.
\end{abstract}

\section{Introduction}

A schwannoma is a benign nerve sheath tumor derived from Schwann cells, the sheath cells that cover myelinated nerve fibers (1). These tumors are typically located in the skin and subcutaneous tissue of the head and neck, or along the flexor surfaces of the extremities (1). Intraosseous schwannomas are rare benign tumors that account for $<1 \%$ of primary bone tumors (2). Fewer than 200 cases have been previously reported; of these cases, the most common sites of the involved bones were the mandible and sacrum (2). Although a number

Correspondence to: Dr Taketoshi Yasuda, Department of Orthopedic Surgery, Faculty of Medicine, University of Toyama, 2630 Sugitani, Toyama 930-0194, Japan

E-mail: yasuda@med.u-toyama.ac.jp

Key words: intraosseous schwannoma, ulna, nutrient vessel of cases of intraosseous schwannoma involving the long bones have been previously reported (3-8), this type of disease is relatively rare, and the typical location at which an intraosseous schwannoma of the long bones may arise is uncertain. Intraosseous schwannoma presents as a slowly enlarging and painless mass (8); however, if the bone becomes affected and a microfracture is caused, the mass becomes painful. Since intraosseous schwannoma is a benign bone tumor, it has good prognosis following surgery with curettage and bone grafting (8).

The radiological findings of intraosseous schwannoma appear as features of benign bone tumors: i) A well-defined lytic lesion with a thin sclerotic margin; ii) trabeculation or multiloculation; iii) cortical expansion; and iv) no internal calcification $(3,4)$. Although it has been reported that pathological fractures are rare in intraosseous schwannoma (4), pathological fractures may occur in slender bones, including the ulna (6). Radiographically, it may be difficult to distinguish intraosseous schwannomas from other benign bone tumors, including solitary bone cyst, aneurysmal bone cyst, giant cell tumor, benign chondroblastoma or fibrous dysplasia (4). On magnetic resonance imaging (MRI), soft tissue schwannomas typically appear isointense to muscle on T1-weighted images and homogeneously or heterogeneously hyperintense to fat on T2-weighted images (9), but not specifically. The tumors may only be diagnosed by microscopic findings, which is difficult without biopsy or surgery $(1,6)$.

Microscopically, the histological characteristics of intraosseous schwannomas are similar to schwannomas in soft tissue $(1,2)$. The tumor is composed of two types of cell arrangement: Antoni A and Antoni B (1,2). The Antoni A area is composed of compactly arranged spindle-shaped and ovoid tumor cells with palisading nuclei known as Verocay bodies, in a fibrous background. The Antoni B area consists of loose cellularity with a myxoid matrix and frequent cystic degeneration and hemorrhage. It is clinically difficult to truly distinguish between soft tissue schwannomas involving the bone and intraosseous schwannomas involving the surrounding soft tissues (4).

Treatment of intraosseous schwannoma is generally performed by curettage or en bloc resection followed by bone grafting. Recurrence is rare, but may be associated with incomplete resection (10). 


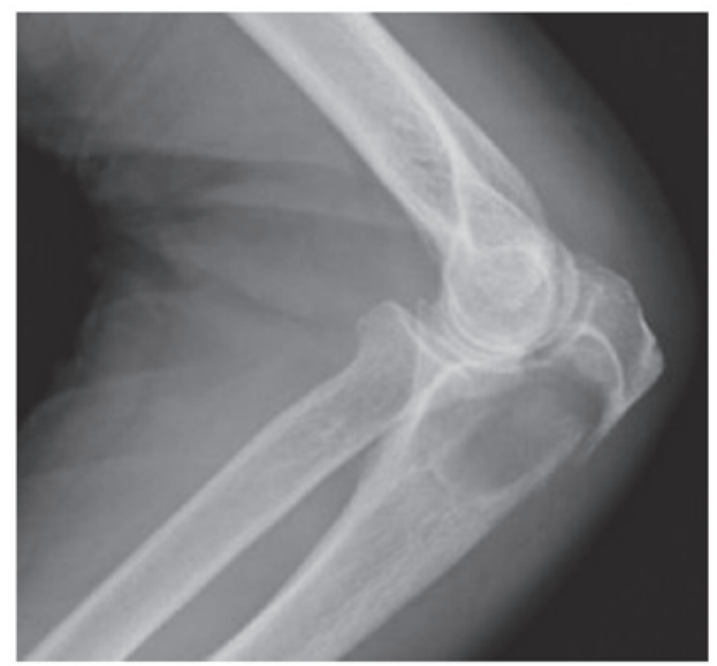

Figure 1. A lateral plain radiograph of the left ulna of an 87-year-old woman. In the proximal metaphysis of the ulna, the plain radiograph revealed a well-defined, lytic lesion with a pathological fracture and no intralesional calcification.
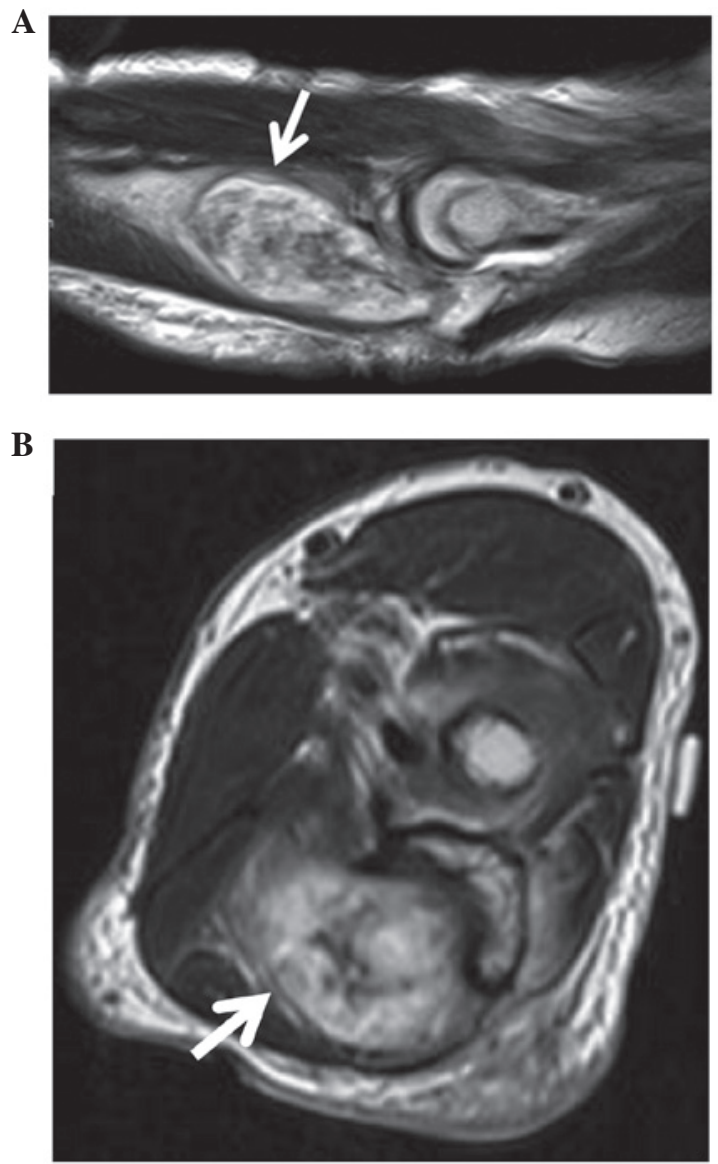

Figure 2. T2-weighted magnetic resonance images of the left proximal forearm. (A) A sagittal plane image revealed a mass with heterogeneous intensity, occurring in the proximal metaphysis of the ulna (arrow). (B) An axial-plane image revealed the mass spreading from the intraosseous lesion to the surrounding soft tissue (white arrow).

Therefore, in the current case report a case of intraosseous schwannoma arising in the ulna is presented. A benign bone tumor was suspected from plain radiographs and MRI,

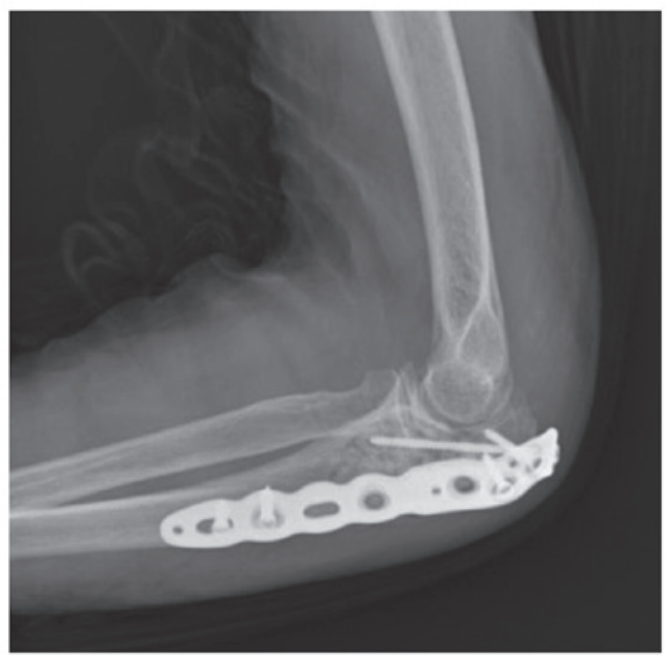

Figure 3. Radiographic observations following surgery. The tumor was marginally resected and curetted, followed by hydroxyapatite granule packing and plate fixation.

and intraosseous schwannoma was diagnosed based on the pathological findings of the surgically resected tumor. In addition, relevant previously reported cases of intraosseous schwannoma involving the long bones in the upper and lower extremities with clear radiographic figures are reviewed. Based on the findings of the present case report and the review of the existing literature, it is possible that the location of intraosseous schwannoma involving the long bones may be determined by the position of the intraosseous artery.

\section{Case report}

In March 2014, an 87-year-old woman presented to Toyama University Hospital (Toyama, Japan) with a 1-month history of a rapidly-growing mass with tenderness on the medial side of her left elbow. On physical examination, there was no limitation of range of motion of the elbow joint and no Tinel's sign detected in the swollen portion. The patient did not demonstrate muscle weakness or sensory disturbance.

Plain radiographs demonstrated a well-defined lytic lesion, with a pathological fracture and no intralesional calcification, in the proximal metaphysis of the left ulna (Fig. 1). The lesion was accompanied by thinning of cortical bone. Computed tomography (CT; SOMATOM ${ }^{\circledR}$ Definition AS; Siemens Healthcare, Erlangen, Germany) confirmed the lesion with cortical expansion and thinning in the proximal metaphysis of the ulna. There was no calcification. MRI (MAGNETOM Avanto; Siemens Healthcare) of the proximal ulna revealed that the intraosseous mass was spreading out from the cortical defect. The lesion appeared isointense to skeletal muscle on T1-weighted images and hyperintense or heterogeneous on T2-weighted images (Fig. 2A and B).

Histological examination of the needle biopsy revealed a benign spindle cell tumor suggestive of a schwannoma. Therefore, marginal resection and curettage, followed by hydroxyapatite granule (REGENOS; Kuraray Co., Ltd., Kurashiki, Japan) packing and plate (VariAx Olecranon Locking Plate; Stryker Japan, Tokyo, Japan) fixation (Fig. 3), was performed. Macroscopically, the encapsulated tumor in 


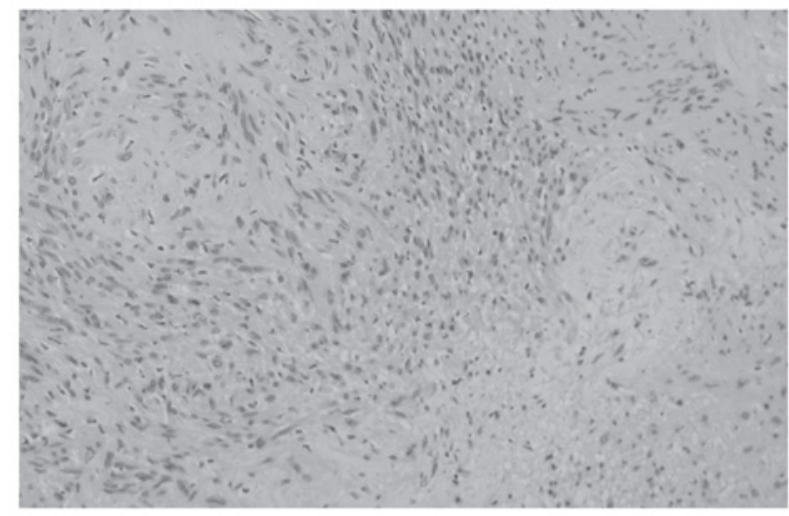

Figure 4. Histopathological results of the resected tumor. The tumor was composed of an Antoni A hypercellular area with a palisading pattern and an Antoni B hypocellular area, with a myxoid stroma (Hematoxylin and eosin staining; magnification, $\mathrm{x} 200$ )

the bone was ovoid and soft, measuring $5 \times 2 \times 1.5 \mathrm{~cm}$. The cut surface of the resected tumor was gray-yellowish and slightly myxomatous. The resected tumor tissue was fixed in formalin, embedded in paraffin, cut into $4-\mu \mathrm{m}$ sections and stained with hematoxylin and eosin (H\&E; Wako Pure Chemical Industries, Ltd., Osaka, Japan). The representative tumor section was immunohistochemically stained with a specific antibody against S-100 protein (polyclonal rabbit; dilution, 1:500; catalog no. Z0311; Dako Japan Co., Tokyo, Japan) using the streptavidin-biotin peroxidase complex method. The H\&E stained section and immunohistochemical staining section were evaluated by two pathologists (Department of Diagnostic Pathology, Faculty of Medicine, University of Toyama, Toyama, Japan). Microscopic examination (Olympus BX61; Olympus Corporation, Tokyo, Japan) confirmed that the tumor was comprised of Antoni A and B areas, with a myxoid stroma (Fig. 4). The tumor cells were positive for S-100 protein on immunohistochemical staining, with only a few cells positive for Mindbomb E3 Ubiquitin Protein Ligase 1. The resected tumor was diagnosed as an intraosseous schwannoma based on these pathological findings. A total of one year subsequent to surgery, the patient exhibits no symptoms, and there is no evidence of disease recurrence.

The present study was conducted following a clinical research review by the ethics committee of the Toyama University Hospital (Toyama, Japan). Written informed consent was obtained from the patient, who was advised that the data from their case would be submitted for publication in the present case report.

\section{Discussion}

Schwannomas typically arise from a peripheral nerve in the skin or the subcutaneous tissue of the head and neck, or along the flexor surfaces of the extremities (1). Intraosseous schwannomas are extremely rare, accounting for $<1 \%$ of total benign bone tumors (2). There is no sex predilection, and $\sim 1 / 2$ of patients who develop intraosseous schwannoma have been reported to be in their second or third decade of life (2). The mandible, maxilla and sacrum are the most common sites of intraosseous schwannoma involvement $(2,11)$. Of a total of 165 cases in five previous review studies, 81 cases (49\%) affected the mandible, $12(7 \%)$ the maxilla, $10(6 \%)$ the sacrum, 40 (24\%) the long bones, $6(4 \%)$ the vertebra, $5(3 \%)$ the rib, $4(2 \%)$ the patella, $3(2 \%)$ the pelvis, $2(1 \%)$ the scapula and $2(1 \%)$ affected other bones $(3,4,10-12)$.

Schwannomas primarily originate from sensory nerves (13). The underlying mechanism of the development of schwannoma involving bone are as follows: i) An extraosseous tumor causes secondary erosion of bone; ii) a tumor arises within the nutrient canal and grows in a dumbbell-shaped configuration, producing enlargement of the canal; and iii) a tumor arises within the bone (3). The reason that the majority of cases involve the mandible may be attributed to the long intraosseous canal of the mandibular nerve, a predominantly sensory nerve (3), and intraosseous schwannomas of the sacrum are associated with the numerous sensory nerve roots that run through the sacral foramina (13). It is often difficult to determine whether the tumor truly originates from bone or arises from the nerve roots and bone is secondarily involved (14). Intraosseous nerves are typically associated with arterial vessels in the nutrient canal and participate in vasomotor functions, and the majority appear to be non-myelinated (15). Therefore, an intraosseous schwannoma involving a long bone may be associated with the second mechanism, the tumor arises and develops within the nutrient canal, and related to the site of the nutrient artery; however, the most common location of intraosseous schwannomas in long bones remains to be elucidated. A total of 4 cases of intraosseous schwannoma of the fibula were previously reported with clear radiographic figures (4-6), and 3 of these cases occurred in the diaphysis of the fibula. As free vascularized fibular grafts have been widely used to cover skeletal bone defects larger than $6 \mathrm{~cm}$ (16), it has been reported that the nutrient canal into the fibula is positioned between 12 and $18 \mathrm{~cm}$ from the tip of the fibula, in the diaphysis (17). Therefore, intraosseous schwannomas of the fibula may be more likely to occur in the diaphysis. The extra- and intraosseous blood supply of the distal radius was investigated by Sheetz et al (18). In that study, the authors observed that certain nutrient arteries were associated with distal radial bone, and they also identified the location of nutrient arteries penetrating cancerous bone. The nutrient arteries in the distal radius usually penetrated cancerous bone at the proximal area to the radiocarpal joint with a distance of 4-21 mm, in the area of epiphysis and metaphysis (18). Therefore, a case of intraosseous schwannoma involving the radius was reported to occur in the distal metaphysis (17). Kimball et al (19) investigated the intraosseous blood supply to the distal humerus. The large nutrient vessels entered the anterior medial diaphysis, an average of $11.4 \mathrm{~cm}$ ( 8 specimens; range, $9.5-14.0 \mathrm{~cm}$ ) proximal to the medial epicondyle $(19)$. The lateral column metaphysis was predominately supplied by posterior segmental vessels, whereas anterior and posterior vessels passed into the medial column metaphysis (19). The trochlea, olecranon fossa and coronoid fossa were watershed areas (19). A total of 2 cases of intraosseous schwannoma of the humerus were reported to arise in the distal metaphysis. One case was in the medial epicondyle and one was in the lateral epicondyle $(8,10)$. Although 8 cases of intraosseous schwannoma involving the ulna have been observed in a large series of reviews $(4,6,7)$, their detailed locations in the 
ulnar bone were unclear. In the present case, the intraosseous schwannoma involving the ulna was located in the proximal metaphysis. This area was supplied by an intraosseous artery, which was a proximal branch from the large nutrient vessel entering the anterior cortex of the ulnar metaphysis in a relatively consistent site at the level of the biceps tuberosity, and was $7.5 \mathrm{~cm}$ distal to the tip of the olecranon (20). The midsubstance of the olecranon appeared to be a relative watershed area for the intraosseous circulation. The tumor in the present case was located in the distal area from the watershed area of the proximal ulna, at a site $9-42 \mathrm{~mm}$ distal to the tip of the olecranon. Therefore, the most common location of intraosseous schwannomas involving long bones may be determined by the position of the intraosseous nutrient artery, particularly by the second mechanism of intraosseous schwannoma; the tumor arises and develops within the nutrient canal.

In conclusion, the present study reported a case of intraosseous schwannoma of the ulnar bone, and the association between the location of intraosseous schwannoma involving long bones and the sites of nutrient vessels in the distal radius, distal humerus, proximal ulna and fibula was considered. Intraosseous schwannoma is able to occur in all long bones, and the most common site of occurrence may be determined by the position of the intraosseous nutrient artery. As it is difficult to totally distinguish intraosseous schwannomas from other benign bone tumors using imaging including plain radiographs and MRI, histological diagnosis by biopsy is necessary.

\section{Acknowledgements}

The present study was supported in part by the Japanese Government Grant-in-Aid for Scientific Research (KAKENHI; grant no. 24592227).

\section{References}

1. Antonescu CR, Perry A and Woodruff JM: Schwannoma (including variants). In: WHO Classification of Tumours of Soft Tissue and Bone. Fletcher CDM, Bridge JA, Hogendoorn P and Mertens F (eds). Vol 5. 4th edition. IARC Press, Lyon, pp170-172, 2013.

2. Unni KK and Inwards CY (eds): Miscellaneous unusual tumors of bone. In: Dahlin's Bone Tumors: General Aspects and Data on 10,165 Cases. 6th edition. Lippincott, Williams \& Wilkins, Philadelphia, PA, pp295-298, 2010.
3. de la Monte SM, Dorfman HD, Chandra R and Malawer M: Intraosseous schwannoma: Histologic features, ultrastructure, and review of the literature. Hum Pathol 15: 551-558, 1984.

4. Ida CM, Scheithauer BW, Yapicier O, Carney JA, Wenger DE, Inwards CY, Bertoni F, Spinner RJ and Unni KK: Primary schwannoma of the bone: A clinicopathologic and radiologic study of 17 cases. Am J Surg Pathol 35: 989-997, 2011.

5. Aoki J, Tanikawa H, Fujioka F, Ishii K, Seo GS, Karakida O and Sone S: Intraosseous neurilemmoma of the fibula. Skeletal Radiol 26: 60-63, 1997.

6. Palocaren T, Walter NM, Madhuri V and Gibikote S: Schwannoma of the fibula. J Bone Joint Surg Br 90: 803-805, 2008.

7. Giné J, Calmet J, Sirvent JJ and Domènech S: Intraosseous neurilemmoma of the radius: A case report. J Hand Surg Am 25: 365-369, 2000 .

8. Mutema GK and Sorger J: Intraosseous schwannoma of the humerus. Skeletal Radiol 31: 419-421, 2002.

9. Stull MA, Moser RP Jr, Kransdorf MJ, Bogumill GP and Nelson MC: Magnetic resonance appearance of peripheral nerve sheath tumors. Skeletal Radiol 20: 9-14, 1991.

10. Wirth WA and Bray CB Jr: Intra-osseous neurilemmoma. Case report and review of thirty-one cases from the literature. $J$ Bone Joint Surg Am 59: 252-255, 1977.

11. Gordon EJ: Solitary intraosseous neurilemmoma of the tibia: Review of intraosseous neurilemmoma and neurofibroma. Clin Orthop Relat Res 117: 271-282, 1976.

12. Zhang L, Xia BQ, Sun H, Wang LZ, Zhao ZL, Li B and Wang XD: Intraosseous schwannomas of the jaws: 2 case reports and review of the literature. Oral Surg Oral Med Oral Pathol Oral Radiol 114: e13-e17, 2012.

13. Turk PS, Peters N, Libbey NP and Wanebo HJ: Diagnosis and management of giant intrasacral schwannoma. Cancer 70: 2650-2657, 1992

14. Unni KK, Inwards CY, Bridge JA, Kindblom LG and Wold LE (eds): Miscellaneous tumors. In: AFIP Atals of Tumor Pathology Series IV: Tumors of the Bones and Joints. 1st edition. Vol 2. ARP Press, Washington DC, pp309-319, 2005.

15. Sherman MS: The nerves of bone. J Bone Joint Surg Am 45: 522-528, 1963.

16. Beris AE, Lykissas MG, Korompilias AV, Vekris MD, Mitsionis GI, Malizos KN and Soucacos PN: Vascularized fibula transfer for lower limb reconstruction. Microsurgery 31: 205-211, 2011.

17. Matsuura M, Ohno K, Michi K, Egawa K and Takiguchi R: Clinicoanatomic examination of the fibula: Anatomic basis for dental implant placement. Int J Oral Maxillofac Implants 14: 879-884, 1999.

18. Sheetz KK, Bishop AT and Berger RA: The arterial blood supply of the distal radius and ulna and its potential use in vascularized pedicled bone grafts. J Hand Surg Am 20: 902-914, 1995.

19. Kimball JP, Glowczewskie F and Wright TW: Intraosseous blood supply to the distal humerus. J Hand Surg Am 32: 642-646, 2007.

20. Hardy BT, Glowczewskie F Jr and Wright TW: Vascular anatomy of the proximal ulna. J Hand Surg Am 36: 808-810, 2011. 